\title{
BAHAN BACAAN DAN ORIENTASI KEAGAMAAN GURU PENDIDIKAN AGAMA ISLAM SMA DI KOTA PALEMBANG
}

\section{READING MATERIAL AND RELIGIOUS ORIENTATION OF THE ISLAM EDUCATION (PAI) TEACHER AT SENIOR HIGH SCHOOLS IN PALEMBANG}

\author{
Zulkarnain Yani \\ Balai Penelitian dan Pengembangan Agama Jakarta \\ Jl. Rawa Kuning No. 6 Pulo Gebang, Cakung, Jakarta Timur \\ email: zulkarnainyani@yahoo.com
}

Naskah Diterima: 25 April 2018; Direvisi: 10 Agustus 2018; Disetujui: 28 Agustus 2018

\begin{abstract}
This paper described research result regarding religious reading materials and religious orientation of Islam Education (PAI) teacher at Senior High School (SMA) in Palembang. Research aimed to obtain the information on reading interest and the variety of reading materials used by the PAI teachers level SMA in Palembang and their religious orientation. Research concluded that the reading interest of the PAI teacher in Palembang, based on their reading materials, is still low. It is due to the lack of references used in teaching-learning process in class. In addition, the religious orientation of the PAI teacher at SMA showed that $51 \%$ or 38 teachers are intrinsic-orientated. They highly respect the purity of heart, vision, understanding, and commitment to clarify the religious rituals. Meanwhile, $49 \%$ or 37 teachers are extrinsic-oriented. They regard religion is used not to receive the blessings of God, but to receive respect from others.
\end{abstract}

Keywords: Reading Materials, Religious Orientation, The PAI teacher, SMA (Senior High School)

\begin{abstract}
Abstrak
Tulisan ini menyajikan hasil penelitian tentang bacaan keagamaan dan orientasi keagamaan guru Pendidikan Agama Islam (PAI) di Sekolah Menengah Atas (SMA) di kota Palembang. Penelitian ini bertujuan untuk memperoleh informasi mengenai minat baca dan ragam bahan bacaan yang digunakan oleh guru-guru mata pelajaran pendidikan agama Islam tingkat SMA yang ada di kota Palembang dan orientasi keagamaan para Guru PAI SMA tersebut. Penelitian ini menyimpulkan bahwa minat baca guru PAI SMA kota Palembang dilihat dari bahan bacaan yang digunakan tergolong rendah karena kurangnya referensi bacaan yang digunakan dalam proses belajar mengajar di kelas. Selain itu, orientasi keagamaan para guru PAI SMA tersebut sebanyak 51\% atau 38 orang guru yang beriorientasi intrinsik, dimana mereka menjunjung tinggi kemurnian hati, visi, pengertian dan komitmen yang memberikan makna pada ritual-ritual keagamaan yang dilakukan dan sebanyak 49\% atau 37 orang guru yang berorientasi ekstrinsik, mereka memandang bahwa agama digunakan bukan untuk meraih keberkahan Tuhan, melainkan supaya orang lain menghargai dirinya.
\end{abstract}

Kata kunci: Bahan Bacaan; Orientasi Keagamaan; Guru Pendidikan Agama Islam; Sekolah Menengah Atas (SMA) 


\section{PENDAHULUAN}

Pada tahun 2016 Balai Penelitian dan Pengembangan Agama Jakarta telah melakukan penelitian "Literatur Guru PAI Tingkat SMA" di 8 (delapan) kota di Tangerang, Serang, DKI Jakarta, Bekasi, Depok, Bogor, Bandung dan Cirebon ${ }^{1}$. Sasaran penelitian pada tahun lalu sebanyak 330 orang GPAI yang sudah tersertifikasi. Penelitian tersebut selain untuk melihat literatur apa saja yang digunakan para guru PAI di dalam menyampaikan materi pelajaran PAI di kelas, juga melihat bagaimana tingkat minat baca guru PAI tersebut berdasarkan bahan-bahan pengayaan yang mereka gunakan. Diperoleh hasil bahwa guru PAI yang ada di kota Bogor dan Cirebon termasuk dalam kategori sedang. Sedangkan kota Tangerang, Serang, DKI Jakarta, Depok, Bekasi dan Bandung termasuk dalam kategori rendah.

Hasil tersebut menunjukkan bahwa minat baca para guru PAI, terutama yang sudah tersertifikasi masih belum membanggakan. Padahal secara finansial guru PAI, selain mendapatkan penghasilan tetap, juga mendapatkan sertifikasi. Padahal dalam UU Nomor 14 tahun 2005 pasal 10 tentang kompetensi guru dan Permendiknas Nomor 16 Tahun 2007 tentang Standar Kualifikasi Akademik dan Kompetensi Guru, disebutkan bahwa seorang guru mata pelajaran harus menggunakan media pembelajaran dan sumber belajar yang relevan dengan karakteristik peserta didik dan mata pelajaran yang diampu untuk mencapai tujuan pembelajaran secara utuh. Terkait dengan sumber belajar tersebut, guru mata pelajaran pendidikan agama Islam harus memiliki kreativitas guna menunjang terselenggaranya proses pembelajaran di kelas dengan menggunakan berbagai ragam literatur dan bahan yang terkait dengan pelajaran pendidikan agama Islam.

Buku adalah jendela dunia. Kunci untuk membukanya adalah membaca. Ungkapan ini secara jelas menggambarkan manfaat membaca, yakni membuka, memperluas wawasan dan pengetahuan seseorang, agar bisa mengetahui lebih tentang dunia yang belum

${ }^{1}$ Zulkarnain Yani dkk. 2016. "Literatur Guru PAI Tingkat SMA". Balai Penelitian dan Pengembangan Agama Jakarta. diketahui sebelumnya. Kegiatan tersebut dapat dilakukan oleh siapa saja, anak-anak, remaja, dewasa, maupun orang-orang yang telah berusia lanjut. Budaya membaca adalah kunci dari kemajuan sebuah bangsa. Kemampuan literasi baca dan tulis adalah syarat utama untuk membangun peradaban karena kemampuan literasi adalah kunci dari ilmu pengetahuan ${ }^{2}$.

Buku merupakan sumber berbagai informasi yang dapat membuka wawasan kita tentang berbagai hal seperti ilmu pengetahuan, ekonomi, sosial, budaya, politik, maupun aspek-aspek kehidupan lainnya. Selain itu, dengan membaca, dapat membantu mengubah masa depan, serta dapat menambah kecerdasan akal dan pikiran. Membaca adalah salah satu kunci penting perkembangan personal, sosial, ekonomi dan kehidupan kewargaan secara umum $^{3}$. Membaca juga dikatakan sebagai bagian dari cara untuk sukses dalam hidup. Pembaca yang baik akan mampu mengembangkan sudut pandang, pengalaman dan pemikirannya. Membaca juga dipandang sebagai sebuah kecakapan tersendiri yang dibutuhkan di dalam dunia yang diarahkan oleh teknologi informasi seperti sekarang ini $^{4}$. Tanpa disadari, manfaat membaca buku dapat memberikan banyak inspirasi bagi kehidupan. Namun sayangnya kegiatan membaca buku akhir-akhir ini telah banyak diabaikan berbagai kalangan dengan alasan kesibukan, maupun karena adanya media yang lebih praktis untuk mendapatkan informasi seperti televisi, radio, maupun media internet ${ }^{5}$.

Pada tahun 2015 Perpustakaan Nasional melakukan penelitian di 12 provinsi dan 28 kabupaten/kota yang mencakup $75 \%$ wilayah Indonesia, yang hasilnya menyatakan bahwa minat baca masyarakat juga menunjukkan

${ }^{2}$ Lidia Endi Sulandari. 2016. "Urgensi Budaya Literasi untuk Membangun Peradaban Suatu Bangsa", http://www.wartaseni.com/2016/06/urgensi-budayaliterasi-untuk-membangun-peradaban-suatubangsa.html, dikutip 19 Agustus 2016.

${ }^{3}$ Christina Clark and Kate Rumbold. (2006). "Reading for Pleasure." National Literacy Trust, November, h. 5.

${ }^{4}$ Zurina Khairuddin 2013 "A Study of Student's Reading Interest in a Second Languange." International Education Studies, Vol. 6 No. 11, h. 160.

${ }^{5}$ Indra dkk. 2016. "15 Manfaat Membaca Buku dalam Kehidupan", http://manfaat.co.id/manfaatmembaca-buku, dikutip 18 Agustus 2016 
angka 25,1 atau kategori rendah ${ }^{6}$. Pada 9 Maret 2016, Central Connecticut State University mempublikasikan hasil penelitian mereka mengenai peringkat minat baca di dunia, dalam data World's Most Literate Nations Indonesia berada di urutan 60 dari 61 negara, diatas negara Botswana ${ }^{7}$. Minat membaca merupakan kebiasaan yang diperoleh setelah seseorang dilahirkan. Dengan demikian, minat membaca bukanlah kebiasaan bawaan. Oleh karena itu, minat membaca dapat dipupuk, dibina dan dikembangkan ${ }^{8}$.

Rendahnya minat baca masyarakat Indonesia ini tidak hanya menimpa kaum miskin dan berpendidikan rendah saja, tapi juga terjadi pada kaum terpelajar, termasuk para guru. Sebagian guru merasa tidak perlu membaca lagi karena sudah selesai kuliah, bukan bidangnya, atau bacaan itu tidak diperlukan di sekolah. Sekalipun mau membaca atau mempelajari sesuatu hanya yang berhubungan dengan tugasnya mengajar atau bidang studi yang diampunya. Sebagian lagi malah merasa terpaksa karena tuntutan sekolah atau harus kuliah lagi untuk mendapat gelar sarjana $^{9}$. Guru yang bermutu ialah guru yang memiliki profesionalitas dalam mengajar peserta didik, yaitu guru yang memiliki kompetensi pengetahuan, kepribadian, sosial, dan keterampilan. Sehingga guru dapat menyampaikan pesan-pesan pendidikan terhadap peserta didiknya dengan baik. Begitu juga dengan guru Pendidikan Agama Islam diharapkan mempunyai kompetensi serupa, sehingga guru agama benar-benar dapat menjadi guru yang bisa digugu dan ditiru ${ }^{10}$.

${ }^{6}$ Syahrul Munir. 2016. "Minat Baca Rendah, Mayoritas Warga Indonesia Hobi Nonton Televisi", (http://regional.kompas.com/read/2016/04/28/21020061/ Minat.Baca.Rendah.Mayoritas.Warga.Indonesia.Hobi.N onton.Televisi), dikutip 18 Agustus 2016.

${ }^{7}$ Millers. 2016. World's Most Literate Nations, http://webcapp.ccsu.edu/?news=1767\&data, dikutip 18 Agustus 2016.

${ }^{8}$ Undang Sudarsana \& Bastiano, 2014 Pembinaan Minat Baca. Tangerang Selatan; Universitas Terbuka, h. vii.

${ }^{9}$ Trimanto. 2016. "Rendahnya Minat Baca di Kalangan Guru", http://halopendidikan.com/rendahnyaminat-baca-di-kalangan-guru/, dikutip 18 Agustus 2016.

${ }^{10}$ M. Rasyid Ridla, 2008 "Profesionalitasn Guru Pendidikan Agama Islam dalam Proses Pembelajaran”, Jurnal Tadris, Vol. 3 No. 1, h. 31.
Guru mata pelajaran pendidikan agama Islam harus mampu menyampaikan materi pelajaran pendidikan agama Islam yang kaya dan komprehensif. Harus mengikuti perkembangan zaman, meng-update informasi, ilmu pengetahuan dan teknologi terbaru supaya bisa menyampaikan materi yang aktual dan kontekstual kepada peserta didik ${ }^{11}$. Sebagaimana yang dilakukan oleh guru-guru Pendidikan Agama Islam SMA di Kabupaten Bandung Barat senantiasa membaca bukubuku terbaru yang berkaitan dengan pelajaran dan mengganti metode pembelajaran dan kreatif dalam menyampaikan materi di kelas ${ }^{12}$.

Berdasarkan penjelasan di atas, ada 2 (dua) pertanyaan yang diajukan; (1) bagaimana minat bacaan keagamaan guru Pendidikan Agama Islam (PAI) tingkat Sekolah Menengah Atas (SMA) yang ada di kota Palembang? (2) bagaimana orientasi keagamaan guru Pendidikan Agama Islam (PAI) tingkat Sekolah Menengah Atas (SMA) tersebut dilihat dari teorinya Gordon W Allport ? Adapun tujuannya adalah untuk memperoleh informasi secara utuh mengenai minat baca dan ragam bahan bacaan yang digunakan oleh guru-guru mata pelajaran pendidikan agama Islam tingkat SMA yang ada di kota Palembang dan orientasi keagamaan para Guru PAI SMA tersebut. Sedangkan kegunaannya adalah untuk memberikan bahan masukan kepada Seksi Pendidikan Agama Islam pada Kementerian Agama kota Palembang terkait minat baca para guru PAI dan orientasi religius para guru PAI tersebut. Sehingga tercipta pengembangan wawasan kebangsaan dan keagamaan yang inklusif.

\section{Kajian Literatur}

Studi atau penelitian mengenai minat baca para guru, khususnya guru PAI tingkat

${ }^{11}$ Idris Apandi. 2016. "Guru dan Budaya Literasi”, http://www.kompasiana.com/idrisapandi/gurudan-budaya-literasi_568cf007f77a614115a384e2

dikutip 15 September 2016, sebagaimana dikutip Zulkarnain Yani pada Makalah Seminar Hasil "Penelitian Literatur Guru Pendidikan Agama Islam Tingkat SMA di Kota Bogor" pada tanggal 17 Nopember 2016.

${ }^{12}$ Saepul Anwar, 2011. "Studi Realitas Tentang Kompetensi Kepribadian Guru Pendidikan Agama Islam Sekolah Menengah Atas di Kabupaten Bandung Barat", Jurnal Ta'lim, Vol. 9 No. 2, h 157. 
SMA, belum sama sekali dilakukan. Dari beberapa kajian yang telah ada, sebagian besar menyoroti minat baca para siswa di sekolah. Kasiyun ${ }^{13}$ mengangkat tema tentang "Upaya Meningkatkan Minat Baca Sebagai Sarana untuk Mencerdaskan Bangsa". Kajian ini membahas cara alternatif meningkatkan minat baca di masyarakat, khususnya di kalangan sekolah, sebagai upaya untuk mengatasi rendahnya minat baca. Menurut Kasiyun, sudah menjadi tanggungjawab bersama antara pustakawan, guru, orang tua, dan masyarakat dalam meningkatkan minat baca bagi siswa dengan terlebih dahulu memberikan keteladanan bagi siswa. Upaya tersebut dimulai dari lingkungan rumah yang menumbuhkan minat baca bagi anak-anak dengan berbagai cara diantaranya mendongeng cerita, mengunjungi toko buku dan membiasakan memberi hadiah berupa buku kepada anak. Di lingkungan sosial dengan menciptakan perpustakaan-perpustakaan kecil. Serta di lingkungan pemerintah dan swasta dengan cara menyelenggarakan perpustakaan, baik perpustakaan sekolah maupun perpustakaan khusus.

Wahyuni $^{14}$ dalam tulisannya mengenai "Menumbuhkan Minat Baca Menuju Masyarakat Literat" mengatakan bahwa di kalangan siswa sekolah belum terbiasa dengan budaya atau kegemaran membaca. Kebanyakan siswa mencari atau membaca buku apabila ada tugas yang diberikan oleh guru di kelas. Tidak adanya upaya pembiasaan membaca di kalangan siswa berimplikasi pada kemampuan mereka dalam membaca. Oleh karena itu, solusi untuk mengatasi rendahnya minat baca anak Indonesia, antara lain; membiasakan anak membaca sejak dini, menyediakan buku/bahan bacaan yang menarik, menciptakan lingkungan yang mendukung kebiasaan membaca, memperbaiki penampilan perpustakaan agar menarik dan mengembangkan model pembelajaran

${ }^{13}$ Suharmono Kasiyun, 2015. "Upaya Meningkatkan Minat Baca Sebagai Sarana untuk Mencerdaskan Bangsa", Jurnal Pena Indonesia. Vol. 1 No. 1, http://journal.unesa.ac.id/index.php/jpi. ISSN: 22477-5150

${ }^{14}$ Sri Wahyuni, 2009. "Menumbuhkan Minat Baca Menuju Masyarakat Literat, Jurnal Diksi, Volume. 16 No. 2. membaca yang menyenangkan, bervariasi, dan mendidik.

Risna $^{15}$ dalam tulisan yang berjudul "Upaya Guru dalam Mengatasi Rendahnya Minat Baca Siswa di Perpustakaan SD Negeri 4 Singkawang Timur". Dalam tulisannya tersebut, Risna mengungkapkan upaya guru dalam mengatasi rendahnya minat baca siswa dan faktor apa saja yang menyebabkan rendahnya minat baca siswa. Hasil penelitiannya menyimpulkan bahwa yang menyebabkan rendahnya minat baca siswa, karena siswa lebih senang berkumpul dengan teman sebaya dari pada membaca buku, siswa menganggap membaca buku dituntut untuk dan diam saja. Upaya yang dilakukan oleh guru adalah mengadakan event atau perlombaan yang membuat siswa gemar membaca dan mencintai buku. Selain itu, Trimanto ${ }^{16}$ mengangkat tulisan tentang "Rendahnya Minat Baca di Kalangan Guru". Dalam tulisannya dia hanya menyampaikan beberapa faktor rendahnya minat baca di kalangan guru. Dia menyebutkan ada lima faktor, yaitu; kurangnya bahan bacaan; daya beli masih rendah; pola pikir (mindset); sikap hidupa (kebiasaan); dan rendahnya motivasi.

Selanjutnya tulisan oleh Solichan Abdullah $^{17}$ yang menulis tentang "Menggalakkan Budaya Membaca Guru Dalam Rangka Pengembangan Keprofesionalan Berkelanjutan”. Dalam tulisannya tersebut, Solichan mengatakan bahwa "Guru profesional tidak lahir dari bentukan sistem, namun guru profesional lahir karena kepribadian yang matang dan berkembang, kesadaran akan pentingnya ilmu pengetahuan dan kecintaannya terhadap profesi yang ditekuninya. Untuk itu perlu dirumuskan satu mekanisme supaya para guru senantiasa

\footnotetext{
${ }^{15}$ Natalia Risna, 2014. "Upaya Guru dalam Mengatasi Rendahnya Minat Baca Siswa di Perpustakaan SD Negeri 4 Singkawang Timur". Jurnal Pendidikan dan Pembelajaran. Vol. 3 No. h. 10.

${ }^{16}$ Trimanto. 2016. "Rendahnya Minat Baca di Kalangan Guru", http://halopendidikan.com/rendahnyaminat-baca-di-kalangan-guru/, dikutip 18 Agustus 2016

${ }^{17}$ Solichan Abdullah. 2011. "Menggalakkan Budaya Membaca Guru Dalam Rangka Pengembangan Keprofesionalan Berkelanjutan". http://www.infodiknas. com/menggalakkan-budaya-membaca-guru-dalam-rang ka-pengembangan-keprofesionalan-berkelanjutan.html, dikutip 22 September 2016.
} 
mengasa kemampuan dan menambah wawasannya. Mekanisme tersebut ada menumbuhkan gerakan membaca bagi para guru. Gerakan membaca perlu diciptakan sebagai upaya untuk meningkatkan kreatifitas, daya analitis, ide-ide inovatif atau memunculkan gagasan-gagasan baru".

Ansyori $^{18}$ dalam tulisannya berjudul "Menumbuhkan Minat Baca Sebagai Upaya Meningkatkan Kualitas Sumber Daya Manusia" menjelaskan secara umum mengenai "upaya konkret dalam meningkatkan minat baca masyarakat Indonesia. Sebagai langkah awal, Dia menyebutkan bisa dikembangkan dari lingkungan keluarga, kemudian beralih ke lingkungan yang lebih luas di masyarakat. Untuk meningkatkan minat baca ini ada baiknya kita meniru budaya yang dikembangkan Jepang. Di sana ada gerakan 20 minutes reading of mother and child. Gerakan ini mengharuskan seorang ibu mengajak anaknya membaca selama 20 menit sebelum tidur. Gerakan ini bisa sangat efektif jika didukung oleh kesadaran yang tinggi, ketersedian buku yang memadai”.

Ridla $^{19}$ dalam tulisannya tentang "Profesionalitas Guru Pendidikan Agama Islam dalam Proses Pembelajaran" lebih menyoroti pada aspek profesionalitas seorang guru Pendidikan Agama Islam harus dapat menjalankan peranannya dengan baik dalam berinteraksi dengan peserta didik, sesama guru, dan staf sekolah, yang dalam hal ini guru Pendidikan Agama Islam dituntut untuk senantiasa bergiat diri dalam meningkatkan pengetahuan dan wawasannya serta profesinya secara terus menerus. Sehingga eksistensi dari guru Pendidikan Agama Islam ini menjadi sosok figur yang dapat mentransfer ilmu pengetahuan sekaligus bisa digugu dan ditiru oleh peserta didik. Profesionalitas seorang guru

${ }^{18}$ Hanif Ridho Ansyori. 2013. "Menumbuhkan Minat Baca Sebagai Upaya Meningkatkan Kualitas Sumber Daya Manusia". http://imadiklus.com/ menumbuhkan-minat-baca-sebagai-upaya-meningkat kan-kualitas-sumber-daya-manusia/, dikutip 19 Agustus 2016.

${ }^{19}$ M. Rasyid Ridla, 2008. "Profesionalitas Guru Pendidikan Agama Islam dalam Proses Pembelajaran", Jurnal Tadris, Vol. 3 No. 1. berorientasi pada peningkatan kualitas dimensi personal dan sosial, termasuk juga pada adanya keseimbangan dengan peningkatan kualitas dimensi intelektual dan profesionalnya.

Anwar $^{20}$ dalam tulisannya mengkaji tentang "Studi Realitas Tentang Kompetensi Kepribadian Guru Pendidikan Agama Islam Sekolah Menengah Atas di Kabupaten Bandung Barat" yang memfokuskan kajiannya pada kompetensi kepribadian guru PAI SMA. Kompetensi kepribadian itu sendiri mengenai karakteristik pribadi yang harus dimiliki oleh seorang guru. Adapun kompetensi kepribadian terkait yang diteliti oleh Anwar mengenai integritas, kemampuan interpersonal, kepemimpinan, kestabilan emosi dan keterbukaan. Hasilnya menunjukkan bahwa guru PAI SMA di Kabupaten Bandung Barat berada dalam kategori tinggi. Artinya kompetensi kepribadian guru Pendidikan Agama Islam menunjukkan kecenderungan ke arah yang positif.

Dari beberapa tulisan dan kajian di atas, belum ada kajian atau penelitian yang khusus mengangkat tema mengenai minat baca guru mata pelajaran Pendidikan Agama Islam untuk tingkat Sekolah Menengah Atas (SMA). Sehingga, penelitian ini sangat jelas posisinya untuk mengetahui seberapa besar perhatian dan minat baca para guru PAI di SMA, khususnya di kota Palembang, Adanya minat baca para guru PAI SMA tersebut bisa dilihat dari ragam pilihan literatur keagamaan yang dipilih dan dijadikan bahan rujukan dalam mengajar dan menyampaikan materi PAI di sekolah masingmasing.

Oleh karena itu, penelitian ini menjadi sangat penting dilakukan untuk mengetahui kondisi para guru PAI SMA di kota Palembang dengan melihat aspek minat baca mereka dan pilihan atau ragam literatur keagamaan yang mereka pilih dan gunakan sebagai bahan atau materi pengajaran PAI di kelas. selain itu, penelitian ini juga melihat orientasi religius dari para guru PAI SMA dengan mengajukan sejumlah pertanyaan/pernyataan.

\footnotetext{
${ }^{20}$ Saepul Anwar, 2011. "Studi Realitas Tentang Kompetensi Kepribadian Guru Pendidikan Agama Islam Sekolah Menengah Atas di Kabupaten Bandung Barat", Jurnal Ta'lim, Vol. 9 No. 2.
} 


\section{METODOLOGI PENELITIAN}

\section{Desain Penelitian}

Penelitian ini menggali seperti apa minat guru PAI dalam membaca bahan keagamaan, dan pilihan bahan bacaan mereka. Serta orientasi keagamaan dengan dilihat dari berbagai aspek seperti yang disebutkan di atas tadi. Penelitian ini menggunakan desain studi kasus kualitatif ${ }^{21}$. Model studi kasus yang digunakan adalah studi kasus kolektif, yakni kasus-kasus yang muncul di lebih dari satu entitas atau individu ${ }^{22}$.

\section{Informan/Partisipan dan Wilayah Penelitian}

Individu-individu itu adalah kolektifitas guru-guru PAI di Sekolah Menengah Atas (SMA), yang sudah sertifikasi. Informan atau partisipan ini berdasarkan informasi yang diperoleh dari Seksi Pendidikan Agama Islam pada kantor Kementerian Agama Kota Palembang.

\section{Pengumpulan Data}

Wawancara semi-terstruktur dilakukan kepada guru-guru PAI SMA dalam satu waktu yang ditentukan. Wawancara dilakukan untuk mengumpulkan data-data tentang minat baca dan ragam literatur yang dibaca serta orientasi keagamaan. Beberapa pertanyaan yang diajukan dalam wawancara adalah mengikuti beberapa indikator dan pertanyaan yang sama yang pernah diajukan untuk meneliti soal minat baca dan pemilihan literatur sebagaimana yang diajukan oleh Purves dan Beach $^{23}$, Wigfield dan Guthrie ${ }^{24}$, Cramer dan Blachowicz ${ }^{25}$, Alam, $\mathrm{dkk}^{26}$, yang secara

${ }^{21}$ Robert, K. Yin. 2003. Case Study Research: Design and Methods. London and New Delhi: Sage Publications, hal. 6-10, 13-15; John W. Creswell, 2007. Qualitative Inquariy and Research Design: Choosing Among Five Approach. London and New Delhi: Sage Publications, hal. 73.

${ }^{22}$ Robert K Yin, Case Study Research. 74.

${ }^{23}$ Alan C Purves \& Richard Beach, Literature and the Reader. hal. 68

${ }^{24}$ Allan, Wigfield., \& John, T. Guthtrie. Dimensions of Children's Motivations for Reading. hal. 15-16.

${ }^{25}$ Eugene, H. Cramer, \& Camille, L.Z. Blachowichz. 1980. Teacher as Readers: An Extension konseptual sudah dijelaskan di dalam kerangka konsep di atas. Tentu saja dengan penyesuaian kalimat dan konteksnya, yakni buku-buku atau literatur keagamaan. Selain wawancara, peneliti juga menyebarkan angket dengan sejumlah pertanyaan. Penggunaan angket tersebut hanya sebagai data pendukung saja.

\section{HASIL DAN PEMBAHASAN}

\section{Gambaran Umum Guru PAI SMA Kota Palembang}

Studi ini menyasar guru-guru PAI SMA di kota Palembang yang sudah tersertifikasi. Berdasarkan data yang diperoleh dari seksi Pendidikan Agama Islam kota Palembang, ada 75 orang guru PAI SMA di kota Palembang yang sudah tersertifikasi. Dari data tersebut, guru PAI yang berjenis kelamin laki-laki sebanyak 34 orang dan 41 orang guru PAI yang berjenis kelamin Perempuan.

Secara kualifikasi tenaga kependidikan, berdasarkan jenjang pendidikan yang dimiliki para guru PAI SMA tersebut sangat bervariatif, mulai dari pendidikan D.3 sampai pendidikan S.3, sebagaimana dapat dilihat pada Tabel 1 .

Berdasarkan data tersebut, masih ada guru PAI SMA di kota Palembang yang memiliki latar belakang pendidikan D.3 yakni 2 orang atau sekitar 3\%. Guru PAI yang berpendidikan S.1 sebanyak 51 orang atau sekitar $68 \%$. Sedangkan yang berpendidikan S.2 sebanyak 21 orang atau sekitar $28 \%$ dan hanya 1 orang guru PAI yang berpendidikan S.3 atau hanya $1 \%$ saja. Tentu saja hasil ini tidak begitu menggembirakan karena kota Palembang sebagai ibukota dari propinsi Sumatera Selatan seharusnya menjadi barometer bagi daerah-daerah lain yang ada di wilayah Sumatera Selatan dalam hal jenjang pendidikan guru, apalagi guru PAI di SMA. Hal ini menjadi perhatian tersendiri pihak Kementerian Agama Kota Palembang, khususnya, dan Kanwil Kementerian Agama propinsi Sumatera Selatan, umumnya, agar dapat lebih mensupport para guru PAI di SMA

\footnotetext{
of the "Impact of Reading" Survey. Reading Horizons. 20(4).

${ }^{26}$ Rudy Harisyah Alam dkk, 2007. Akses Literatur Keagamaan pada Masyarakat Muslim. Jakarta: Balai Penelitian dan Pengembangan Agama.
} 
untuk meneruskan pendidikan mereka ke jenjang S.2 dan S.3.

Tabel 1. Guru PAI SMA Kota Palembang berdasarkan jenjang pendidikan

\begin{tabular}{|c|c|c|c|c|}
\hline Jenis Kelamin & D.3 & S.1 & S.2 & S.3 \\
\hline Laki-Laki (org) & 1 & 20 & 12 & 1 \\
\hline Perempuan (org) & 1 & 31 & 9 & - \\
\hline Jumlah & 2 & 51 & 21 & 1 \\
\hline
\end{tabular}

\section{Sumber Pengetahuan Keagamaan Guru PAI SMA Kota Palembang}

Sebagai informasi tambahan, peneliti juga menggali informasi mengenai darimana para guru PAI SMA tersebut menambah pengetahuan agama mereka. Berdasarkan hasil yang diperoleh, para guru PAI SMA dalam menambah pengetahuan agama mereka sangat bervariasi sebagai berikut.

Tabel 2. Sumber pengetahuan keagamaan guru PAI SMA Kota Palembang

\begin{tabular}{|c|c|}
\hline Sumber Pengetahuan Agama & Jumlah (org) \\
\hline $\begin{array}{l}\text { Mengikuti kelompok pengajian di lingkungan/kantor/tempat usaha dan } \\
\text { membaca buku-buku atau literatur agama (majalah, buletin, jurnal keagamaan) }\end{array}$ & 2 \\
\hline Mengikuti kelompok pengajian di lingkungan/kantor/tempat usaha & 2 \\
\hline $\begin{array}{l}\text { Mengikuti kelompok pengajian di lingkungan/kantor/tempat usaha, membaca } \\
\text { buku-buku atau literatur agama (majalah, buletin, jurnal keagamaan) dan } \\
\text { belajar di Pesantren }\end{array}$ & 1 \\
\hline $\begin{array}{l}\text { Mengikuti kelompok pengajian di lingkungan/kantor/tempat usaha, membaca } \\
\text { buku-buku atau literatur agama (majalah, buletin, jurnal keagamaan), } \\
\text { menonton/mendengarkan siaran keagamaan di televisi/radio dan melalui media } \\
\text { sosial (BBM/Whatsapp/Facebook/ Line/Twitter) }\end{array}$ & 19 \\
\hline $\begin{array}{l}\text { Mengikuti kelompok pengajian di lingkungan/kantor/tempat usaha dan } \\
\text { menonton/mendengarkan siaran keagamaan di televisi/radio dan belajar di } \\
\text { Pesantren }\end{array}$ & 1 \\
\hline Membaca buku-buku atau literatur agama (majalah, buletin, jurnal keagamaan) & 5 \\
\hline $\begin{array}{l}\text { Membaca buku-buku atau literatur agama (majalah, buletin, jurnal keagamaan) } \\
\text { dan melalui media sosial (BBM/Whatsapp/Facebook/ Line/Twitter) }\end{array}$ & 4 \\
\hline $\begin{array}{l}\text { Mengikuti kelompok pengajian di lingkungan/kantor/tempat usaha dan } \\
\text { membaca buku-buku atau literatur agama (majalah, buletin, jurnal keagamaan). } \\
\text { dan menonton/mendengarkan siaran keagamaan di televisi/radio }\end{array}$ & 11 \\
\hline $\begin{array}{l}\text { Membaca buku-buku atau literatur agama (majalah, buletin, jurnal keagamaan) } \\
\text { dan menonton/mendengarkan siaran keagamaan di televisi/radio }\end{array}$ & 8 \\
\hline $\begin{array}{l}\text { Membaca buku-buku atau literatur agama (majalah, buletin, jurnal } \\
\text { keagamaan), menonton/mendengarkan siaran keagamaan di televisi/radio dan } \\
\text { melalui media sosial (BBM/Whatsapp/Facebook/ Line/Twitter) }\end{array}$ & 8 \\
\hline Menonton/mendengarkan siaran keagamaan di televisi/radio & 3 \\
\hline $\begin{array}{l}\text { Mengikuti kelompok pengajian di lingkungan/kantor/tempat usaha, membaca } \\
\text { buku-buku atau literatur agama (majalah, buletin, jurnal keagamaan) dan } \\
\text { melalui media sosial (BBM/Whatsapp/Facebook/Line/Twitter) }\end{array}$ & 1 \\
\hline $\begin{array}{l}\text { Mengikuti kelompok pengajian di lingkungan/kantor/tempat usaha dan media } \\
\text { sosial (BBM/Whatsapp/Line/Facebook/Twitter) }\end{array}$ & 2 \\
\hline $\begin{array}{l}\text { Mengikuti kelompok pengajian di lingkungan/kantor/tempat usaha, } \\
\text { menonton/mendengarkan siaran keagamaan di televisi/radio dan melalui media } \\
\text { sosial (BBM/Whatsapp/Line/Facebook/Twitter) }\end{array}$ & 2 \\
\hline $\begin{array}{l}\text { Belajar di pesantren dan menonton/mendengarkan siaran keagamaan di } \\
\text { televisi/radio }\end{array}$ & 1 \\
\hline
\end{tabular}




\begin{tabular}{|l|c|}
\hline \multicolumn{1}{|c|}{ Sumber Pengetahuan Agama } & Jumlah (org) \\
\hline $\begin{array}{l}\text { Menonton/mendengarkan siaran keagamaan di televisi/radio dan melalui media } \\
\text { sosial (BBM/Whatsapp/Line/Facebook/Twitter) }\end{array}$ & 2 \\
\hline Melalui media sosial (BBM/Whatsapp/Facebook/Line/Twitter) & 1 \\
\hline $\begin{array}{l}\text { Mengikuti kelompok pengajian di lingkungan/kantor/tempat usaha, membaca } \\
\text { buku-buku atau literatur agama (majalah, buletin, jurnal keagamaan), } \\
\text { menonton/mendengarkan siaran keagamaan di televisi/ radio dan belajar di } \\
\text { pesantren }\end{array}$ & 1 \\
\hline Lain-Lain Jumlah & 75 \\
\hline \multicolumn{1}{|c|}{} \\
\hline
\end{tabular}

Ada sekitar 60 orang guru PAI SMA yang masih menjadi buku sebagai sumber pengetahuan agama mereka, sedangkan yang lainnya sangat bervariatif. Ada guru yang menjadi media sosial sebagai sumber pengetahuan agama mereka. Ada guru yang menjadikan siaran di televisi atau radio sebagai sumber pengetahuan agama mereka dan lain sebagainya. Jumlah 60 orang guru tersebut bila diprosentasekan sekitar 80\% guru PAI SMA di kota Palembang yang masih menjadikan buku sebagai bahan, rujukan dan sumber pengetahuan agama mereka dan bisa dikategorikan "bagus".

\section{Bahan Bacaan Keagamaan Guru PAI SMA Kota Palembang}

Berdasarkan hasil wawancara dengan para guru PAI SMA kota Palembang, diperoleh informasi, selain buku paket PAI yang digunakan, mengenai berbagai ragam bahan bacaan keagamaan yang digunakan para guru PAI SMA tersebut di dalam menyampaikan materi pelajaran PAI di kelas.

\section{Materi Al-Qur'an Hadits}

Untuk materi Al-Qur'an dan Hadits, bahan bacaan yang digunakan sangat beragam dan variatif. Ada 24 judul yang menjadi bahan bacaan para guru PAI SMA untuk materi alQur'an, adapun bahan bacaan tersebut sebagai berikut : PAI dan Buku Pekerti; Al-Qur'an dan Terjemahan terbitan Kementerian Agama (=dulu Departemen Agama); Al-Qur'an dan Terjemah terbitan Rabithah Alam Islami Maktab; Al-Qur'an VS Sains Modern Menurut Dr. Zakir Naim; Al-Qur'an dan Hadits; Terjemah Majmu' al-Syarif; Tematis Ensiklopedia Al-Qur'an; Tafsir al-Qur'an; ArRazaq; Al-Qur'an Nur Karim terbitan Imam
Nawawi; Tafsir dan Makna Doa-Doa dalam Al-Qur'an; AL-Qur'an dan Terjemahannya beserta Tafsirnya karya Haidar Nasir; 50 Kaidah Al-Qur'an; Al-Qur'an Terjemah dan Tajwid; Tafsir al-Azhar, Al Islam Kemuhammadiyah; Tafsir al-Maraghy; Tafsir al-Misbah; Al-Qur'an Tafsir Perkata Tajwid; Al-Qur'an/Hadist; Kedudukan Al-Qur'an Sebagai Sumber Hukum; Al-Qur'anku dengan Tajwid Blok Warna Edisi 2; Pendidikan AlIslam Untuk SMA/SMK/MA Muhammadiyah; Kiat Bersahabat dengan Al-Qur'an dan Agama Islam dan Budi Pekerti.

Al-Qur'an dan Terjemah terbitan Kementerian Agama menjadi pilihan yang paling banyak dipakai dan digunakan para guru PAI SMA di dalam memperkaya dan memperdalam materi al-Qur'an hadits, selain itu Al-Qur'an dan terjemah terbitan terbitan Rabithah Alam Islami Maktab juga digunakan oleh beberapa guru PAI, tafsir al-Misbah, tafsir al-Maraghy serta Pendidikan Al-Islam Untuk SMA/SMK/MA Muhammadiyah.

\section{Materi Aqidah}

Adapun materi Aqidah, terdapat sejumlah bahan bacaan yang dipakai dan digunakan oleh para guru PAI SMA tersebut. Ada 21 karya atau buku yang menjadi bahan bacaan guru-guru PAI SMA, antara lain; Quantum Ridha; I'tibar Kesejukan Hati Kemuliaan Pribadi Terhadap Ridho Ilahi karya M. Khalid Isabir; Aqidah Muslim karya alGhazali; Aqidah Islamiyah karya Sayyid Sabra; Buku Induk Aqidah Islam karya Syaikh Muhammad bin Shalih Al Utsaimin rohimuhullah terbitan Dar al-Haq; Terjemah Minhajul Abidin Petunjuk Ahli Ibadah karya Imam Al-Ghazali; 50 Mujizat Rasulullah karya Fuad Kauma; Aqidah Muslim diterjemahkan 
oleh Mahyuddin Syaf; Menata Hati; Aqidah Islam Pola Hidup Manusia Beriman karya Sayid Sabiq; Nailul Authar 1-6 terjemahan Mu'ammal Hanidi; Kehidupan Sosial Menurut Islam karya Mustafa Husni As-Syibai; I'tiqod Ahli Sunah Wal Jama'ah karya KH. Siradjudin Abbas; Asma'ul Husna; Atlas Agama karya Dr. Syauqi Abu Khatif; Tasawuf Modern, Imam Ghazali; Aqidah Akhlak terbitan PP Muhammadiyah; Menggapai Manisnya Iman karya Syekh Soleh; Misteri \& Keajaiban Ka'bah karya Dr. Abad Badruzaman; Mengenal Allah karya Prof, Muhammad Ratib al-Nablusi; Ensiklopedia Pendidikan Syirah \& Terjemahan Riyadus Sholihin Imam Nawawi; Aqidah dan Sunnah karya Din Syamsuddin.

Ada beberapa buku yang selalu muncul dan disampaikan oleh guru-guru PAI SMA tersebut, diantaranya; Quantum Ridha; I'tibar Kesejukan Hati Kemuliaan Pribadi Terhadap Ridho Ilahi karya M. Khalid Isabir; Aqidah Akhlak terbitan PP Muhammadiyah; Buku Induk Aqidah Islam karya Syaikh Muhammad bin Shalih Al Utsaimin rohimuhullah terbitan Dar al-Haq; Aqidah dan Sunnah karya Din Syamsuddin; Aqidah Islamiyah karya Sayyid Sabra dan Terjemah Minhajul Abidin Petunjuk Ahli Ibadah karya Imam Al-Ghazali.

\section{Materi Akhlaq}

Ada 31 bahan bacaan keagamaan untuk materi Akhlaq yang dipakai dan digunakan para guru PAI SMA kota Palembang, bukubuku menjadi rujukan tersebut, antara lain ; Hadits-Hadits Pilihan untuk Remaja karya Khabib Basori; Bimbingan Akhlak Putra \& Putri karya Umar Baradja; Rasulullah Teladan Umat; Akhlak Muslim karya Ummul Ihsan; Adab dan Akhlak Islami karya Majid Saud; Ihya 'Ulumuddin Imam al-Ghazali; Psikologi Akhlak karya Ibn Hasan Al-Andalusia; Tanbihul Ghafilin Pembangunan Jiwa dan Moral karya al-Faqih Abu Laits Samar Qandi; Dhurratun Nasihin karya Abu H.F. Ramadian BA; Pendidikan Islam Tradisi dan Modernisasi di tengah Tantangan Millenium III karya Azyumardi Azra; Kehidupan Sosial Menurut Islam karya Mustafa Husni Assibai; Nailul Authar 1-6 terjemahan Mu'ammal Hanidi; Integrasi Budi Pekerti Dalam Pendidikan Agama Islam karya Khursan Haliddhi dan Abdurrahman Said; Akhlak Tasawuf Karya
Jami, MA; Berpakaian Muslim dan Muslimah; Aqidah Akhlak terbitan PP Muhammadiyah; Akhlaqul Karimah untuk SMA terbitan PP Muhammadiyah; Syajaah karya M. Ridwan; Hormat, Patuh pada Orang Tua dan Guru karya R. Hidayat; Materi Akhlak karya Barmawie Hurary; Pedoman Hidup Islami terbitan PP Muhammadiyah; Akhlaqul Karimah untuk SMA terbitan PP Muhammadiyah; Menjadi Kekasih Allah karya Marohaan Ahmad; Pendidikan Al-Islam Untuk SMA/SMK/MA Muhammadiyah karya Muh. Rifzi Rosyidi dan Muh. Kholil; Himpunan Fadilah Amal karya Maulana Muhammad Zakaria Al Kandalani; Membentuk Pribadi Lebih Islami (Suatu Kajian Akhlak) karya Ridwan Asy-Syirbaani; Berlaku Jujur karyaAminudin Muh.Sugana HS dan Slamet Abidin; Akhlaq Sehari-hari karya Ma'Sunantun Hikmah; Ensiklopedia Pendidikan Akhlak Mulia: Panduan Mendidik Anak Menurut Metode Islam 1-6 karya Syeikh DR. Abdullah Nasih Ulwan; Agama Islam dan Budi Pekerti karya Rahmat Kamal dan Akhlakul Karim karya Nashih Al-Ukwan.

Ada beberapa bahan bacaan yang sering dijadikan rujukan dan referensi para guru PAI SMA dalam menyampaikan materi Akhlaq, diantaranya; Aqidah Akhlak terbitan PP Muhammadiyah; Pedoman Hidup Islami terbitan PP Muhammadiyah; Pendidikan AlIslam Untuk SMA/SMK/MA Muhammadiyah karya Muh. Rifzi Rosyidi dan Muh. Kholil; Akhlaqul Karimah untuk SMA terbitan PP Muhammadiyah Keempat buku tersebut banyak dijadikan referensi oleh beberapa guru PAI SMA yang kebetulan mereka merupakan guru PAI di SMA Aisyiyah dan SMA Muhammadiyah yang ada di kota Palembang. Sehingga materi Akhlag, sebagaimana materi al-Qur'an dan Aqidah, menggunakan bukubuku terbitan PP Muhammadiyah.

\section{Materi Fiqih}

Untuk materi Fiqih, Ada 18 buku yang menjadi bahan bacaan para guru PAI SMA untuk materi fiqih di kelas, antara lain; Fiqih Islam karya Sulaiman Rasjid; Ilmu Fiqih Islam Lengkap karya Moh. Rifa'i; Masail Fiqhiyah karya Masjfuk Zuhdi; Terjemah \& Penjelasan Bidayatul Hidayah karya KH. Yahya Al Mutamakkin; Fiqh 5 Mazhab Jilid 2 karya M. Jawad Mughniyah; Ush Fiqh karya Romli SA; 
Ushul Fiqh karya A. Hanafie; Praktek Ekonomi dalam Islam karya M. Ridwan dan R. Hidayat; Pelaksanaan Tata Cara Penyelenggaraan Jenazah karya M. Ridwan; Pelaksanaan Khutbah Tabliq dan Dakwah karya R. Hidayat; Sirajul Wahhaj karya Muhammad Zuhri Al-Ghumrowi; Fiqh Imam Syafi'i (Mengupas Masalah Fiqhiyah Berdasarkan Al-Qur'an dan Hadits) terjemahan kitab alFiqh al-Syafi'i al-Muyassar karya Wahbah Zuhaili; Pendidikan Al-Islam Untuk SMA/ SMK/MA Muhammadiyah karya Muh. Rifzi Rosyidi dan Muh. Kholil; Ibadah-Ibadah Wajib karya Sarpaji Pandu; Munakahat/pernikahan karya Aminuddin; Minhajul Muslimin karya Syeikh Abu Bakar Ar Jaja'in; Agama Islam dan Budi Pekerti dan Rahmat Kamal dan Kajian Masalah Shalat karya Sulaiman.

Ada beberapa buku yang sering disebut oleh guru-guru PAI SMA tersebut, yaitu; Fiqih Islam karya Sulaiman Rasjid. Buku paling banyak disebut oleh guru-guru tersebut karena materi yang ada di dalam buku sangat jelas, padat dan simpel untuk dipahami para siswa, sehingga guru lebih memilih menggunakan buku tersebut dibandingkan dengan buku-buku yang lain. Buku Ilmu Fiqih Islam Lengkap karya Moh. Rifa'i juga menjadi pilihan lain guru dalam memperkaya materi Fiqih di kelas.

Selain buku yang mencakup seluruh materi tentang fiqih, ada juga beberapa guru yang memilih buku tematik tertentu seperti; Praktek Ekonomi dalam Islam karya M. Ridwan dan R. Hidayat; Pelaksanaan Tata Cara Penyelenggaraan Jenazah karya $M$. Ridwan; Pelaksanaan Khutbah Tabliq dan Dakwah karya R. Hidayat; Ibadah-Ibadah Wajib karya Sarpaji Pandu; Munakahat/ pernikahan karya Aminuddin. Pemilihan buku tersebut dalam rangka untuk mempermudah dan memfokuskan pembahasan materi fiqih di kelas. Selain itu, ada juga guru PAI SMA yang hanya menggunakan buku paket PAI yang sudah ada karena menurut mereka materi fiqih yang ada di dalam buku sudah cukup memadai untuk diajarkan kepada siswa.

\section{Materi SKI/SPI}

Adapun bahan bacaan yang menjadi materi pengayaan PAI SMA di kelas ada 22 buku yang dipakai dan digunakan, antara lain; Sejarah Peradaban Islam karya Badri Yatim;
Terjemah Tarikh Al Rasyri Al-Islam karya Mudhari Bik Ali Bahad dan Moh. Zuhri; Sumbangan Peradaban Islam pada Dunia karya Raghib As-Sirjani; Tarikh Al-Tasyia Al-Islamy karya Muh. Zuhri; Buku Induk Terlengkap Agama Islam, Sawarna karya Tim Kajian Keislaman Nurul Ilmu; Sejarah Peradaban Islam, Hudhari Bik Ali Bahad Drs. Muh. Zuhri; Kelengkapan Tarikh karya $\mathrm{H}$. Maenawar Chalil; Sejarah Kebudayaan Islam Kelas X karya Imam Subchi; Sejarah Peradaban Islam karya Samsul Munir Amin; Pendidikan Agama Islam Untuk SMA karya Husni Thoyor; Khazanah Peradaban Islam karya Musthafa Husni; Perjuangan Rasulullah SAW di Mekkah; Riwayat Kehidupan Muhammad karya Al Hamid Al Husaini; Sejarah Kebudyaan Islam karya Harun Nasution; Dakwah Rasulullah di Mekkah dan di Madinah; Al Islam dan Kemuhammadiyahan; Sejarah Pendidikan \& Peradaban Islam karya Hanus Asrohah; Tokoh-Tokoh Besar Islam Sepanjang Sejarah (Terjemahan) karya Syaikh Muhammad Sa'id Mursi; Pendidikan Tarikh, Widayanto, Majelis Pendidikan Dasar dan Menengah PP Muhammadiyah; Pendidikan Al-Islam Untuk SMA/SMK/MA Muhammadiyah karya Muh. Rifzi Rosyidi, Lc, M.Ag, Muh. Kholil, M.Pd.I, Majelis Dikdasmen Jawa Timur; Meneladani Perjuangan Rasul karya Ma'Sunatun; Sejarah dan Peradaban Islam karya Al-Arkaun; Kemajuan dan Kemunduran Peradaban Islam di Dunia karya Nurlailah.

Buku Sejarah Peradaban Islam karya Badri Yatim menjadi pilihan yang paling banyak dipakai dan digunakan para guru PAI SMA, buku ini salah satu buku yang isi materinya sangat mudah untuk dipahami dan dipelajari, baik oleh guru dan siswa. Selain itu, ada beberapa buku lainnya yang digunakan disamping buku-buku yang sifatnya langsung tematik menyesuaikan dengan materi PAI SMA seperti buku Dakwah Rasulullah di Mekkah dan di Madinah; Perjuangan Rasulullah SAW di Mekkah; Tokoh-Tokoh Besar Islam Sepanjang Sejarah dan beberapa buku lainnya.

Berdasarkan bahan bacaan keagamaan yang dipakai dan digunakan para guru PAI SMA di kota Palembang di atas, dapat diperoleh informasi bahwa para guru PAI 
SMA tersebut menggunakan beragam bahan bacaan sebagai pengayaan dan pendalaman materi PAI selain buku paket PAI yang ada. Bila disimpulkan, guru PAI SMA kota Palembang lebih banyak memperkaya materi Akhlaq di dalam menyampaikan materi PAI di kelas, yakni sebanyak 31 bahan bacaan atau

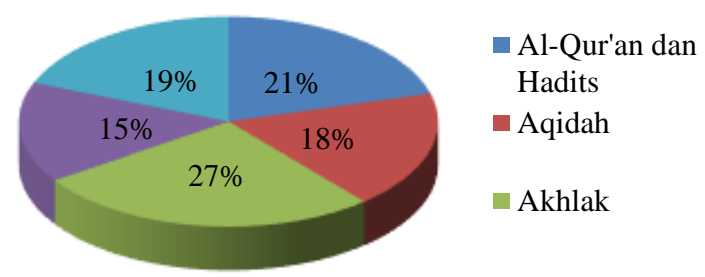

sekitar 27\%, materi al-Qur'an sebanyak 24 bahan bacaan atau sekitar $21 \%$, materi SKI/SPI sebanyak 22 bahan bacaan atau sekitar 19\%, materi Aqidah sebanyak 21 bahan bacaan atau sekitar $18 \%$ dan materi Fiqih sebanyak 18 bahan bacaan atau sekitar $15 \%$.

Al-Qur'an dan

Hadits

Akhlak

\section{Gambar 1. Sumber bahan bacaan keagamaan Guru PAI SMA Kota Palembang}

Terkait dengan hasil tersebut di atas dan dihubungkan dengan minat baca, dengan menggunakan teori minat baca model AIDA ${ }^{27}$; attention, interest, desire and action, maka diperoleh hasil bahwa para Guru PAI SMA di kota Palembang lebih memperkaya materimateri yang berhubungan dengan akhlaq. Hal itu ditunjukkan dengan banyaknya bahan bacaan yang berkaitan dengan materi akhlaq yang dijadikan bahan rujukan atau referensi mereka di dalam mengajar materi PAI di kelas. Hal tersebut bisa dipengaruhi beberapa faktor, diantaranya faktor usia para guru PAI SMA yang rata-rata kelahiran antara tahun 1950 1979. Hanya 2 orang guru PAI SMA saja yang kelahiran di tahun 1980an. Tentu saja faktor usia turut mempengaruhi pemahaman keagamaan mana yang lebih diutamakan dalam penyampaian materi bagi siswa di kelas. Dalam hal ini, guru PAI SMA Kota Palembang lebih mengutamakan materi Akhlaq dilihat dari aspek afektif (sikap) dan psikomotorik (tindakan).

\section{Orientasi Keagamaan Guru PAI SMA Kota Palembang}

Orientasi keagamaan yang dipahami sebagai pemaknaan seseorang terhadap agamanya, dalam konteks hubungan antar umat ber-

${ }^{27}$ Onong Uchjana Effendy, 2013. Ilmu Komunikasi Teori dan Praktik, Bandung: PT. Remaja Rosda Karya, h. 15. agama, dapat mendorong seseorang yang beragama dalam dua kecenderungan; menjadi pribadi yang damai dan bersahabat atau menjadi pribadi yang menyimpan prasangka (prejudice) dan rasa permusuhan.

Orientasi keagamaan ini selanjutnya dapat mengarahkan individu pada dua sikap pula, yang pertama sikap inklusif, moderat, dan respek terhadap keyakinan yang berbeda, sedangkan yang kedua adalah sikap eksklusif dan keras atau radikal. Demikian pula halnya kedua sikap tersebut pada gilirannya dapat mempengaruhi cara individu tersebut berperilaku dalam kehidupan sehari-hari, termasuk ketika berinteraksi dengan orang lain, baik yang seagama maupun berbeda agama ${ }^{28}$.

Gordon W Allport ${ }^{29}$ membagi dua macam cara beragama: Ekstrinsik dan Intrinsik. Ekstrinsik memandang agama sebagai sesuatu yang dapat dimanfaatkan. Agama berguna untuk mendukung kepercayaan diri, memperbaiki status, bertahan melawan kenyataan, atau memberi sanksi pada suatu cara hidup. Orang dengan orientasi itu menemukan bahwa agama bermanfaat dalam

\footnotetext{
${ }^{28}$ Sekar Ayu Aryani, 2015. “Orientasi, Sikap dan Perilaku Keagamaan”, Jurnal Religi, Vol. XI No. 1, Yogyakarta; Fakultas Ushuluddi dan Pemikiran Islam UIN Sunan Kalijaga, h. 59.

${ }^{29}$ Robert W. Crapps, Dialog Psikologi dan Agama, 1993. dari judul An Introduction to Psychology of Religion, diterjemahkan oleh A.M. Hardjana, Yogyakarta: Kanisius, h. $179-181$.
} 
banyak hal, dan menekankan "hadiah" apa yang diperoleh mengatasi apa yang dituntutnya. Orang-orang semacam itu mungkin rajin ke tempat ibadat tetapi tak berminat membicarakan atau memikirkan iman mereka melebihi keuntungan dan manfaat praktisnya. Agama ekstrinsik adalah agama yang diperalat atau dimanfaatkan.

Sedangkan yang intrinsik, adalah cara beragama yang memasukkan ke dalam dirinya nilai-nilai ajaran agama. Nilai-nilai dari ajaran agama terhujam ke dalam jiwanya. Adanya internalisasi nilai-nilai spiritualitas keagamaan. Agama adalah penghayatan batin kepada Tuhan yang memiliki pengaruh dalam sikap hidup sehari-hari. Karena ibadah ritual keagamaan bukan praktik tanpa makna, bukan kulit tanpa isi. Dengan demikian, cara beragama yang intrinsik-lah yang mampu melahirkan kepedulian sosial terhadap sesama yang penuh dengan kasih sayang. Adanya penghayatan dan pengimplementasian terhadap pelaksanaan nilai-nilai ritual-formal keagamaan itu sendiri.

Tabel 3. Daftar pertanyaan orientasi keagamaan guru PAI SMA Kota Palembang

\begin{tabular}{|c|c|c|c|}
\hline No & PERNYATAAN & $\mathrm{TS}$ & $\mathrm{KS} / \mathrm{AS}$ \\
\hline 1 & Saya berdzikir untuk mempertebal keimanan. & & \\
\hline 2 & $\begin{array}{l}\text { Saya dengan sukarela memberi sedekah kepada } \\
\text { siapapun. }\end{array}$ & & \\
\hline 3 & $\begin{array}{l}\text { Untuk menambah wawasan keagamaan, saya } \\
\text { mengikuti majelis taklim. }\end{array}$ & & \\
\hline 4 & $\begin{array}{l}\text { Saya mengerjakan shalat sunnah agar lebih dekat } \\
\text { kepada Tuhan. }\end{array}$ & & \\
\hline 5 & Setelah melaksanakan sholat saya merasa lebih tenang. & & \\
\hline 6 & $\begin{array}{l}\text { Saya menghentikan sejenak kegiatan mengajar ketika } \\
\text { adzan berkumandang. }\end{array}$ & & \\
\hline 7 & Mengajarkan agama kepada orang lain adalah ibadah. & & \\
\hline 8 & $\begin{array}{l}\text { Saya merasa bersyukur ketika dapat membantu orang } \\
\text { lain. }\end{array}$ & & \\
\hline 9 & $\begin{array}{l}\text { Saya mengingatkan teman yang menunda sholat } \\
\text { meskipun ia tidak menyukainya. }\end{array}$ & & \\
\hline 10 & Saya sholat Duha agar usaha lancar. & & \\
\hline 11 & $\begin{array}{l}\text { Saya tambah rajin beribadah ketika menghadapi banyak } \\
\text { cobaan. }\end{array}$ & & \\
\hline 12 & $\begin{array}{l}\text { Saya tidak peduli teman yang meninggalkan sholat } \\
\text { asalkan hubungan kami tetap baik. }\end{array}$ & & \\
\hline 13 & $\begin{array}{l}\text { Saya memulai pekerjaan dengan berdoa agar lancar dan } \\
\text { sukses. }\end{array}$ & & \\
\hline 14 & $\begin{array}{l}\text { Tidak masalah bagi saya menunda sholat asalkan } \\
\text { pekerjaan cepat selesai. }\end{array}$ & & \\
\hline 15 & $\begin{array}{l}\text { Agar hubungan baik terjaga saya membantu orang } \\
\text { lain. }\end{array}$ & & \\
\hline 16 & Ketika tertimpa musibah, saya protes kepada Tuhan. & & \\
\hline 17 & Saya bersedekah agar rezeki lancar. & & \\
\hline 18 & $\begin{array}{l}\text { Setelah sholat saya merasa lega karena telah } \\
\text { melaksanakan kewajban. }\end{array}$ & & \\
\hline 19 & Agar kenginan mudah tercapai saya sholat Tahajud. & & \\
\hline 20 & $\begin{array}{l}\text { Saya aktif mengikuti majlis taklim untuk menambah } \\
\text { teman. }\end{array}$ & & \\
\hline
\end{tabular}



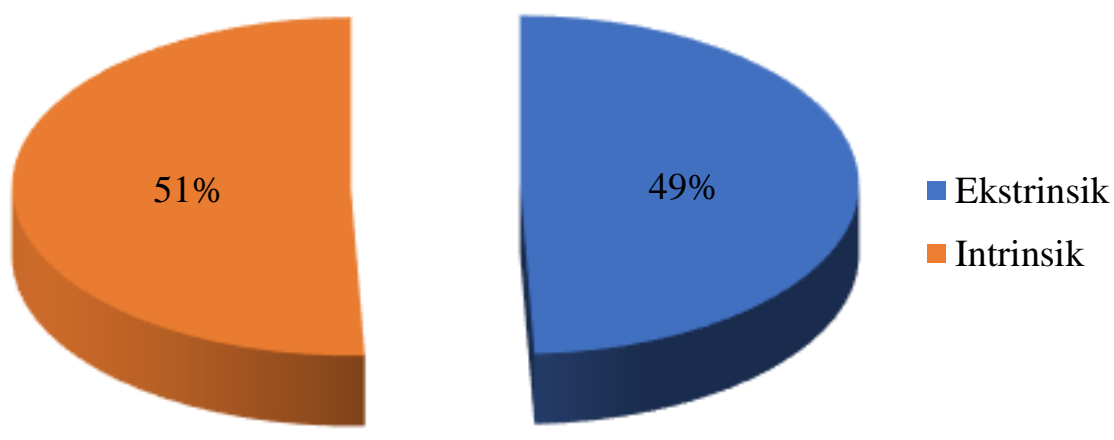

Gambar 2. Orientasi keagamaan guru PAI SMA Kota Palembang

Untuk melihat orientasi keagamaan guru PAI SMA yang ada di Kota Palembang, peneliti menanyakan sejumlah pertanyaan/pernyataan kepada para guru PAI SMA dengan pilihan jawaban; Tidak Sesuai, Kurang Sesuai/Agak Sesuai dan Sesuai. Adapun pertanyaan yang diajukan dapat dilihat pada Tabel 3.

Gambar 2. menunjukkan bahwa sebanyak 37 orang guru PAI SMA yang orientasi keagamaan ke ekstrinsik, dimana mereka memandang bahwa agama digunakan bukan untuk meraih keberkahan Tuhan, melainkan supaya orang lain menghargai dirinya. Dia beragama demi status sosial, demi harga diri, demi gengsi, bahkan agar terlihat saleh di tengah-tengah komunitas umat beragama. Tak pelak, ajaran agama pun tidak menghujam ke dalam dirinya.

Sedangkan 38 orang guru PAI SMA lainnya berorientasi keagamaan yang instrinsik, dimana para guru PAI SMA tersebut menjunjung tinggi kemurnian hati, visi, pengertian dan komitmen yang memberikan makna pada ritual-ritual keagamaan yang dilakukan. Dengan demikian agama memiliki kekuatannya sendiri dan dalam ukuran tertentu memberi arah dalam hidup. Individu intrinsik memiliki harga diri karena mampu mengikuti nilai norma dan moral yang diyakini olehnya. Mereka hidup dengan penuh percaya diri, mampu menerima kritik dengan baik dan mempunyai keyakinan akan kemampuan untuk mengatasi masalah dalam kehidupan, karna hidupnya dengan berpegang pada komitmen dan memiliki prinsip dalam menjalankan $\operatorname{agamanya}^{30}$.

\section{PENUTUP}

\section{Kesimpulan}

Berdasarkan hasil pembahasan di atas, minat baca para guru PAI SMA yang ada di kota Palembang masih tergolong rendah karena kurangnya referensi bacaan yang digunakan dalam proses belajar mengajar di kelas. Untuk materi al-Qur'an, para guru PAI SMA banyak menggunakan Al-Qur'an dan Terjemah terbitan Kementerian Agama, adapun materi Fiqih mereka menggunakan buku Fiqih Islam karya Sulaiman Rasjid, materi Sejarah Peradaban/Kebudayaan Islam menggunakan buku Sejarah Peradaban Islam karya Badri Yatim dan materi Aqidah dan Akhlaq menggunakan buku Quantum Ridha dan Aqidah Akhlak terbitan PP Muhammadiyah.

Adapun mengenai orientasi religius/ keagamaan; diperoleh hasil yang kurang begitu menggembirakan. Dimana orientasi beragama yang ekstrinsik dengan intrinsik tidak ada perbedaan yang signifikan. Tentu saja ini sebagai bahan penelitian lebih lanjut untuk memperdalam aspek-aspek lainnya yang mempengaruhi orientasi religius/keagamaan guru PAI SMA seperti itu.

${ }^{30}$ Dedeh Rosmiyati, 2002. "Perbedaan Harga Diri ditinjau Dari Orientasi Religiusitas EkstrinsikIntrinsik”, Skripsi, Jurusan Psikologi, Universitas Komputer Indonesia, https://repository.unikom.ac.id/4312/, dikuitp Kamis 7 Desember 2017. 


\section{Saran \& Rekomendasi}

Ada beberapa saran yang dapat disampaikan disini berdasarkan hasil penelitian ini. Untuk meningkatkan minat baca para guru PAI di Sekolah Menengah Atas (SMA), khususnya di wilayah kota Palembang dan sekitarnya, agar dilakukan Diklat atau Pembinaan Minat Baca di lingkungan guru PAI SMA yang diselenggarakan oleh Balai Diklat Keagamaan Palembang. Diklat atau pembinaan tersebut bertujuan untuk menumbuhkembangkan pentingnya meningkatkan minat baca berbagai bahan bacaan keagamaan sebagai materi pengayaan PAI di kelas. Terkait tentang orientasi religius atau keagamaan guru PAI SMA, perlu diberikan pembinaan dan pemahaman keagamaan yang moderat di lingkungan guru PAI SMA. Sehingga, penyampaian materi-materi PAI di kelas lebih mengutamakan materi yang berwawasan kebangsaan, keanekaragaman dan menghargai perbedaan antar sesama pemeluk agama Islam di bidang ibadah dan muamalah sehari-hari.

\section{UCAPAN TERIMA KASIH}

Ucapan terima kasih peneliti sampaikan kepada berbagai pihak yang telah membantu selama proses penelitian ini, antara lain :

1. Kepala Balai Litbang Agama Jakarta; yang telah memberikan kepercayaan kepada peneliti untuk melakukan penelitian ini di kota Palembang. Tak lupa Kasubag TU beserta staf Balai Litbang Agama Jakarta yang telah membantu administrasi pelaksanaan penelitian ini.

2. Kepala Kementerian Agama kota Palembang, Kasubang Tata Usaha, Kasi Pendidikan Agama Islam beserta staf yang telah membantu peneliti selama mengumpulkan materi dan data terkait penelitian ini.

3. Pengurus MGMP PAI SMA kota Palembang yang turut membantu kelancaran pelaksanaan penelitian ini.

4. Para Guru PAI SMA kota Palembang yang bertindak sebagai informan dalam penelitian; terima kasih telah meluangkan waktunya untuk bercengkrama dengan peneliti selama berada di lokasi penelitian dan diganggu jam mengajarnya.

5. Kepada semua pihak yang tidak dapat peneliti sebutkan satu persatu, terima kasih.

\section{DAFTAR PUSTAKA}

\section{Buku/Jurnal}

Alam, Rudy Harisyah, dkk. (2007). Akses Literatur Keagamaan pada Masyarakat Muslim. Jakarta: Balai Penelitian dan Pengembangan Agama Jakarta

Anwar, Saepul., (2011). "Studi Realitas Tentang Kompetensi Kepribadian Guru Pendidikan Agama Islam Sekolah Menengah Atas di Kabupaten Bandung Barat". Jurnal Ta'lim. Vol. 9 No. 2.

Aryani, Sekar Ayu., (2015). "Orientasi, Sikap dan Perilaku Keagamaan”, Jurnal Religi, Vol. XI No. 1, Yogyakarta; Fakultas Ushuluddi dan Pemikiran Islam UIN Sunan Kalijaga

Clark, Christina, Kate Rumbold. (2006). "Reading for Pleasure." National Literacy Trust, November.

Cramer, Eugene H.\& Camille L.Z. Blachowichz., (1980). "Teacher as Readers: An Extension of the "Impact of Reading" Survey." Reading Horizons, Vol. 20, Iss. 4.

Crapps, Robert W., (1993). Dialog Psikologi dan Agama, dari judul An Introduction to Psychology of Religion, diterjemahkan oleh A.M. Hardjana. Yogyakarta: Kanisius Creswell,

John W., (2007). Qualitative Inquariy and Research Design: Choosing Among Five Approach. London and New Delhi: Sage Publications.

Effendy, Onong Uchjana., (2013). Ilmu Komunikasi Teori dan Praktik, Bandung: PT. Remaja Rosda Karya

Purves, Alan C., Richard Beach. (1972). Literature and the Reader: Research in Respone to Literature, Reading Interest, and the Teaching of Literature. UrbanaChampaign: University of Illinois.

Kasiyun, Suharmono., (2015). "Upaya Meningkatkan Minat Baca Sebagai Sarana untuk Mencerdaskan Bangsa", Jurnal Pena Indonesia. Vol. 1 No. 1. ISSN: 22477-5150

Khairuddin, Zurina., (2013). "A Study of Student's Reading Interest in a Second Languange." International Education Studies, Vol. 6, No. 11 
Sudarsana \& Bastiano, Undang., (2014). Pembinaan Minat Baca. Tangerang Selatan; Universitas Terbuka.

Ridla, M. Rasyid., (2008). "Profesionalitasn Guru Pendidikan Agama Islam dalam Proses Pembelajaran", Jurnal Tadris, Vol. 3 No. 1.

Risna, Natalia., (2014). Upaya Guru dalam Mengatasi Rendahnya Minat Baca Siswa di Perpustakaan SD Negeri 4 Singkawang Timur. Jurnal Pendidikan dan Pembelajaran. Vol. 3 No. 10.

Wahyuni, Sri., (2009). "Menumbuhkan Minat Baca Menuju Masyarakat Literat, Jurnal Diksi, Vol. 16 No. 2.

Wigfield, Allan, John T. Guthtrie. (1995). "Dimensions of Children's Motivations for Reading: An Initial Study." Reading Research Report, No. 34.

Yin, Robert K., (2003). Case Study Research: Design and Methods, London and New Delhi: Sage Publications

\section{Internet}

Abdullah, Solichan., (2011) "Menggalakkan Budaya Membaca Guru Dalam Rangka Pengembangan Keprofesionalan Berkelanjutan", http://www.infodiknas.com/menggalakka n-budaya-membaca-guru-dalam-rangkapengembangan-keprofesionalanberkelanjutan.html, dikutip 22 September 2016.

Ansyori, Hanif Ridho. (2013). "Menumbuhkan Minat Baca Sebagai Upaya Meningkatkan Kualitas Sumber Daya Manusia”. http://imadiklus.com/menumbuhkanminat-baca-sebagai-upayameningkatkan-kualitas-sumber-dayamanusia/, dikutip 19 Agustus 2016.

Apandi, Idris., (2016). "Guru dan Budaya Literasi", http://www.kompasiana.com/idrisapandi/ guru-dan-budaya-

literasi_568cf007f77a614115a384e2, dikutip 15 September 2016, sebagaimana dikutip Zulkarnain Yani pada Makalah Seminar Hasil "Penelitian Literatur Guru Pendidikan Agama Islam Tingkat SMA di Kota Bogor" pada tanggal 17 Nopember 2016.

Dedeh Rosmiyati, (2002). "Perbedaan Harga Diri ditinjau Dari Orientasi Religiusitas Ekstrinsik-Intrinsik”, Skripsi, Jurusan Psikologi, Universitas Komputer Indonesia, 2002, https://repository.unikom.ac.id/4312/, dikutip Kamis 7 Desember 2017.

Indra dkk. (2016). "15 Manfaat Membaca Buku dalam Kehidupan", http://manfaat.co.id/manfaat-membacabuku, dikutip 18 Agustus 2016.

Munir, Syahrul. (2016). Minat Baca Rendah, Mayoritas Warga Indonesia Hobi Nonton Televisi.

(http://regional.kompas.com/read/2016/0 4/28/21020061/Minat.Baca.Rendah.May oritas.Warga.Indonesia.Hobi.Nonton.Tel evisi), dikutip 18 Agustus 2016.

Sulandari, Lidia Endi. (2016). "Urgensi Budaya Literasi untuk Membangun Peradaban Suatu Bangsa", http://www.wartaseni.com/2016/06/urge nsi-budaya-literasi-untuk-membangunperadaban-suatu-bangsa.html, dikutip 19 Agustus 2016.

Trimanto. (2016). "Rendahnya Minat Baca di Kalangan Guru", http://halopendidikan.com/rendahnyaminat-baca-di-kalangan-guru/, dikutip 18 Agustus 2016.

Millers. (2016). "World's Most Literate Nations".

http://webcapp.ccsu.edu/?news $=1767 \& d$ ata, dikutip 18 Agustus 2016. 